\title{
Survey of arthropod assemblages responding to live yeasts in an organic apple orchard
}

\author{
Stefanos S. Andreadis ${ }^{*}$, Peter Witzgall and Paul G. Becher \\ Chemical Ecology Unit, Department of Plant Protection Biology, Swedish University of Agricultural Sciences, Alnarp, Sweden
}

OPEN ACCESS

Edited by:

Thomas Seth Davis,

University of Idaho, USA

Reviewed by:

Dong H. Cha,

Cornell University/SUNY-ESF, USA

Qing-He Zhang

Sterling International, Inc., USA

${ }^{*}$ Correspondence: Stefanos S. Andreadis ssa18@psu.edu

${ }^{\dagger}$ Present Address: Stefanos S. Andreadis, Chemical Ecology Lab,

Department of Entomology, Pennsylvania State University, University Park, PA, USA

Specialty section: This article was submitted to Chemical Ecology,

a section of the journal

Frontiers in Ecology and Evolution

Received: 23 August 2015 Accepted: 09 October 2015 Published: 26 October 2015

Citation:

Andreadis SS, Witzgall $P$ and Becher PG (2015) Survey of arthropod assemblages responding to

live yeasts in an organic apple orchard. Front. Ecol. Evol. 3:121. doi: 10.3389/fevo.2015.00121
Associations between yeasts and insect herbivores are widespread, and these inter-kingdom interactions play a crucial role in yeast and insect ecology and evolution. We report a survey of insect attraction to live yeast from a community ecology perspective. In the summer of 2013 we screened live yeast cultures of Metschnikowia pulcherrima, M. andauensis, M. hawaiiensis, M. lopburiensis, and Cryptococcus tephrensis in an organic apple orchard. More than 3000 arthropods from 3 classes, 15 orders, and 93 species were trapped; ca. $79 \%$ of the trapped specimens were dipterans, of which $43 \%$ were hoverflies (Syrphidae), followed by Sarcophagidae, Phoridae, Lauxaniidae, Cecidomyidae, Drosophilidae, and Chironomidae. Traps baited with $M$. pulcherrima, M. andauensis, and C. tephrensis captured typically 2.4 times more specimens than control traps; traps baited with $M$. pulcherrima, $M$. hawaiiensis, $M$. andauensis, $M$. lopburiensis, and $C$. tephrensis were more species-rich than unbaited control traps. We conclude that traps baited with live yeasts of the genera Metschnikowia and Cryprococcus are effective attractants and therefore of potential value for pest control. Yeast-based monitoring or attract-and-kill techniques could target pest insects or enhance the assemblage of beneficial insects. Manipulation of insect behavior through live yeast cultures should be further explored for the development of novel plant protection techniques.

Keywords: yeast baited traps, Mestchnikowia, Cryptococcus, hoverflies, drosophilids

\section{INTRODUCTION}

Yeasts are widely distributed in most terrestrial and aqueous environments (Lachance, 2006). They are found on plant leaves (Limtong and Koowadjanakul, 2012), ephemeral flowers (Lachance et al., 2001), floral nectars (Pozo et al., 2011), as well as on animals (Ahearn, 1998; Yaman and Radek, 2008). Yeasts associated with insects not only provide nutritional services (Callaham and Shifrine, 1960; Barker et al., 1988; Rohlfs and Kürschner, 2010; Becher et al., 2012; Stensmyr et al., 2012; Witzgall et al., 2012) but also benefit from insects that disperse them to new habitats (Lachance et al., 2001; Ganter, 2006; Buser et al., 2014). Volatile yeasts metabolites mediate these mutualistic interactions with insects (Davis et al., 2013; Buser et al., 2014; Christiaens et al., 2014).

Metschnikowia yeasts are commonly found on fruits, flowers and in nectar (Ethiraj et al., 1980; Manson et al., 2007; de Vega et al., 2012; Kaewwichian et al., 2012), where they encounter insects (Lachance et al., 2005; Nguyen et al., 2006; de Vega et al., 2012). So far, 39 Metschnikowia species are known to be associated with flower-visiting insects (Kaewwichian et al., 2012; Guzmán et al., 2013). Among these, $M$. pulcherrima is associated with several species, including the codling moth 
Cydia pomonella (Lepidoptera: Tortricidae) (Witzgall et al., 2012; Knight and Witzgall, 2013) and the green lacewing Chrysoperla rufilabris (Burmeister) (Neuroptera: Chrysopidae) (Woolfolk and Inglis, 2004).

Yeast species of the genus Cryptococcus can be found in the soil (Vishniac, 2002) or in the phyllosphere of several plants (Fonseca and Inácio, 2006). They are associated with bromeliads (Landell et al., 2009) as well as fruit trees including apple (Malus domestica), pear (Pyrus spp.), and plum (Prunus spp.) where they have been found on fruits, blossoms, or leaves (Vadkertiová et al., 2012). Some Cryptococcus species are associated with beetles (Ganter, 2006), and C. tephrensis has been isolated from frass and larval galleries of the codling moth (Witzgall et al., 2012).

Yeast-invertebrate associations have been known for decades, yet only few specific ecological interactions are studied in depths (Ganter, 2006), and the potential of yeast for pest control has been rarely exploited. Yeasts play a crucial role in host finding in insect herbivores and a wide range of insects respond olfactorily to volatile emissions from yeasts (Witzgall et al., 2012; Davis et al., 2013; Buser et al., 2014). Herein, we report attraction of arthropods to traps baited with five yeast species in an organic apple orchard. The overall research objectives were to survey the arthropod species composition and abundance, and the specificity of attraction to different yeasts.

\section{MATERIALS AND METHODS}

\section{Study Site}

The study site was a 25-year-old organic apple orchard (cvs. Aroma and Discovery) located in Alnarp, Southern Sweden $\left(55^{\circ} 39.602^{\prime} \mathrm{N}\right.$ latitude, $13^{\circ} 4.688^{\prime} \mathrm{E}$ longitide; $7 \mathrm{~m}$ above sea level).

\section{Yeast Species and Cultivation}

The yeast species used in our study are shown in Table 1. Four species belonged to the genus Metschnikowia (Ascomycota, Saccharomycetes) and one species to the genus Cryptococcus (Basidiomycota, Tremellomycetes). Stocks of all yeast cultures were stored at $-80^{\circ} \mathrm{C}$ in $15 \%$ glycerol.

Starting cultures $(50 \mathrm{ml})$ for inoculation of Petri dishes $(3.5 \mathrm{~cm}$ diameter) were grown in a defined synthetic minimal medium (Merico et al., 2007) in $250 \mathrm{ml}$ Erlenmeyer flasks at $26^{\circ} \mathrm{C}$ with the aeration maintained by shaking at $380 \mathrm{rpm}$ for approximately $40-$ $44 \mathrm{~h}$ in a rotative shaker (VWR ${ }^{\circledR}$ Incubating Mini Shaker, VWR International, USA). Yeast growth was followed by measuring the optical density at a wavelength of $600 \mathrm{~nm}\left(\mathrm{OD}_{600 \mathrm{~nm}}\right)$ (SPECTROstar Nano, BMG LABTECH, Ortenberg, Germany).

\section{Trapping with Live Yeast Cultures}

Live yeast cultures were prepared for tests of arthropod attraction by streaking $100 \mu \mathrm{l}$ of the fermented starting cultures (at $\mathrm{OD}_{600 \mathrm{~nm}}$ 1.2-1.4) from $M$. pulcherrima, M. andauensis, $M$. hawaiiensis, M. lopburiensis, and C. tephrensis isolates onto Petri dishes (3.5 cm diameter) containing 5-10 ml YPD agar $\left(20 \mathrm{gL}^{-1}\right.$ peptone, $20 \mathrm{gL}^{-1}$ glucose, $10 \mathrm{gL}^{-1}$ yeast extract, and $20 \mathrm{gL}^{-1}$ agar). The dishes were incubated in a dark climate chamber at $24^{\circ} \mathrm{C}$ for $72 \mathrm{~h}$. Dishes containing only YPD agar were prepared as a control.

All trapping experiments using live cultures consisted of six treatments which were cultures of (i) M. pulcherrima, (ii) M. andauensis, (iii) M. hawaiiensis, (iv) M. lopburiensis, (v) C. tephrensis, and (vi) media control. Arthropod responses to these live culture treatments were tested six times from late June to early September 2013, every 2 weeks (Figure S1). Petri dishes were placed in delta traps $(12 \times 10 \times 18 \mathrm{~cm}$, white body and sticky bottom; PheroNet AB, Alnarp, Sweden) and traps were rotated within a site on each trapping date by shifting positions in the line (i.e., the first trap moved to the second trap's position, trap two moved to trap three's location, and so forth). Traps were hung from the apple tree branches at ca. $1.5 \mathrm{~m}$ height, with a distance of ca. $5 \mathrm{~m}$ between traps. Each treatment was replicated 10 times at each of the trapping dates. Traps were checked daily. After 5 days traps were collected and all captured specimens were determined. Most specimens were identified to family, many of them to genus and species, based on morphological criteria.

\section{Statistical Analysis}

All statistical tests incorporate a Type I error rate of $\alpha=0.05$, and all parametric statistics were carried out using Proc GLM in SAS version $9.4^{\odot} 2013$ (SAS Institute, Cary, NC, USA). Specimen abundance, species richness, as well as the effect of yeast cultures on the attraction of individuals in the families Syrphidae, Chironomidae, Sarcophagidae, Cecidomyidae, Drosophilidae, Tephritidae, Phoridae, and Lauxaniidae were examined by a

TABLE 1 | Yeast strains used for trapping of arthropods in an organic apple orchard in Alnarp, Sweden, June-September 2013.

\begin{tabular}{|c|c|c|c|c|c|}
\hline Genus & Species & Accession no. & Origin & Substrate of isolation & References \\
\hline \multirow[t]{4}{*}{ Metschnikowia } & pulcherrima & CBS 5833 & $\mathrm{CBS}^{\mathrm{a}}$ & Vitis labrusca berries & Pitt and Miller, 1968 \\
\hline & andauensis & CBS 10809 & $\mathrm{CBS}^{\mathrm{a}}$ & Helicoverpa armigera larval gut, Ostrinia nubilalis larval feces & Molnár and Prillinger, 2005 \\
\hline & hawaiiensis & CBS 7432 & $\mathrm{CBS}^{\mathrm{a}}$ & Ipomoea acuminate flowers & Lachance et al., 1990 \\
\hline & lopburiensis & SPODO 4 & SLUb & Spodoptera frugiperda larval feces & \\
\hline Cryptococcus & tephrensis & NRRL Y 48787 & $\mathrm{ARS}^{\mathrm{C}}$ & Apple orchard & \\
\hline
\end{tabular}

${ }^{a}$ CBS stands for CBS Collection (Centraal Bureau voor Schimmelcultures, Utrecht, the Netherlands).

${ }^{b} S L U$ stands for SLU Collection (Swedish University of Agricultural Sciences, Alnarp, Sweden).

${ }^{c}$ ARS stands for Agricultural Research Service Culture Collection (United States Department of Agriculture, Peoria, IL). 


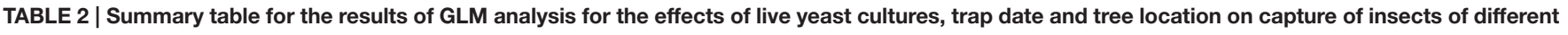
families in an organic apple orchard.

\begin{tabular}{|c|c|c|c|c|c|c|c|c|c|c|c|c|}
\hline \multirow[t]{2}{*}{ Factor } & \multicolumn{3}{|c|}{ Syrphidae } & \multicolumn{3}{|c|}{ Chironomidae } & \multicolumn{3}{|c|}{ Sarcophagidae } & \multicolumn{3}{|c|}{ Cecidomyiidae } \\
\hline & $d f$ & $\boldsymbol{F}$ & $P$ & $d f$ & $\boldsymbol{F}$ & $P$ & $d f$ & $\boldsymbol{F}$ & $P$ & $d f$ & $\boldsymbol{F}$ & $P$ \\
\hline Yeast & 5 & 6.04 & $<0.001$ & 5 & 8.65 & $<0.001$ & 5 & 4.04 & 0.0015 & 5 & 5.16 & $<0.001$ \\
\hline Date & 4 & 72.26 & $<0.001$ & 4 & 11.83 & $<0.001$ & 5 & 7.48 & $<0.001$ & 5 & 8.97 & $<0.001$ \\
\hline YeastDate & 20 & 5.31 & $<0.001$ & 20 & 8.52 & $<0.001$ & 25 & 2.57 & $<0.001$ & 25 & 2.43 & 0.0003 \\
\hline Location & 9 & 1.57 & 0.1263 & 9 & 0.70 & 0.7085 & 9 & 1.59 & 0.1192 & 9 & 2.32 & 0.0159 \\
\hline \multirow[t]{3}{*}{ Yeast*Location } & 45 & 0.81 & 0.8007 & 45 & 0.95 & 0.5680 & 45 & 1.21 & 0.1789 & 45 & 0.68 & 0.9372 \\
\hline & \multicolumn{3}{|c|}{ Drosophilidae } & \multicolumn{3}{|c|}{ Tephritidae $^{a}$} & \multicolumn{3}{|c|}{ Phoridae } & \multicolumn{3}{|c|}{ Lauxaniidae } \\
\hline & $d f$ & $\boldsymbol{F}$ & $\boldsymbol{P}$ & $d f$ & $F$ & $\boldsymbol{P}$ & $d f$ & $\boldsymbol{F}$ & $\boldsymbol{P}$ & $d f$ & $F$ & $\boldsymbol{P}$ \\
\hline Yeast & 5 & 2.91 & 0.0214 & 5 & 3.12 & 0.0102 & 5 & 2.02 & 0.0754 & 5 & 5.99 & $<0.001$ \\
\hline Date & 1 & 20.02 & $<0.001$ & 4 & 9.24 & $<0.001$ & 5 & 31.87 & $<0.001$ & 5 & 2.68 & 0.0222 \\
\hline YeastDate & 5 & 3.07 & 0.0164 & 20 & 2.89 & $<0.001$ & 25 & 0.80 & 0.7401 & 25 & 0.60 & 0.9350 \\
\hline Location & 9 & 2.16 & 0.0401 & 9 & 0.99 & 0.4530 & 9 & 1.64 & 0.1033 & 9 & 1.39 & 0.1929 \\
\hline Yeast*Location & 45 & 0.76 & 0.8295 & 45 & 0.77 & 0.8528 & 45 & 0.77 & 0.8549 & 45 & 1.06 & 0.3820 \\
\hline
\end{tabular}

${ }^{a}$ Tephritid fruit flies were mainly represented by Rhagoletis cerasi.

TABLE 3 | Summary table for the results of GLM analysis for the effects of live yeast cultures, trap date and tree location on specimen abundance and species richness of arthropods in an organic apple orchard.

\begin{tabular}{|c|c|c|c|c|c|c|}
\hline \multirow[t]{2}{*}{ Factor } & \multicolumn{3}{|c|}{ Specimen abundance } & \multicolumn{3}{|c|}{ Species richness } \\
\hline & $d f$ & $\boldsymbol{F}$ & $\boldsymbol{P}$ & $d f$ & $\boldsymbol{F}$ & $\boldsymbol{P}$ \\
\hline Yeast & 5 & 10.31 & $<0.001$ & 5 & 7.27 & $<0.001$ \\
\hline Date & 5 & 52.99 & $<0.001$ & 5 & 11.57 & $<0.001$ \\
\hline YeastDate & 25 & 4.20 & $<0.001$ & 25 & 1.69 & 0.0230 \\
\hline Location & 9 & 1.65 & 0.1001 & 9 & 0.94 & 0.4950 \\
\hline Yeast*Location & 45 & 0.84 & 0.7619 & 45 & 1.31 & 0.0988 \\
\hline
\end{tabular}

generalized linear model (GLM) with a Poisson error distribution with treatment $(n=6)$ as a fixed effect, while trap position (tree location) $(n=10)$ and trapping date $(n=6)$ were considered as blocking factors. Multiple comparisons of means were made using Tukey's honestly significant difference (HSD) test. For analyses of individual arthropod families trap data were only considered for dates where specific catches were above zero since we were not as strongly interested in distinguishing effects of date of capture or tree location as we were in the efficacy of live yeast cultures, but we did wish to partition these sources of variation in the models (Tables 2, 3) (Domingue et al., 2015).

\section{RESULTS}

A total number of 3266 arthropods were captured during the sampling period, 89.6\% Insecta, 7.6\% Entognatha, and 2.8\% Arachnida. Concerning insect orders, the composition of trap catches was $88.1 \%$ Diptera, $4.0 \%$ Hymenoptera, $1.9 \%$ Hemiptera, $1.5 \%$ Thysanoptera, and $1.4 \%$ Lepidoptera (Table 4). The
TABLE 4 | Number of arthropods by order [classification is based on Tree of Life Web Project (Maddison and Schulz, 2007)] captured in trapping experiments with live yeast cultures of the genera Metschnikowia and Cryptococcus.

\begin{tabular}{|c|c|c|c|c|c|c|c|c|}
\hline \multirow[t]{2}{*}{ Taxa } & \multirow[t]{2}{*}{ Order } & \multicolumn{7}{|c|}{ Total no. of specimens per treatment ${ }^{a}$} \\
\hline & & MP & MA & $M H$ & $M L$ & $C T$ & C & Total \\
\hline Entognatha & Collembola & 36 & 35 & 54 & 53 & 38 & 32 & 248 \\
\hline \multirow[t]{11}{*}{ Insecta } & Dermaptera & 10 & 2 & 3 & 4 & 8 & 5 & 32 \\
\hline & Orthoptera & 5 & 2 & 5 & 1 & 4 & 0 & 17 \\
\hline & Psocoptera & 0 & 0 & 1 & 1 & 2 & 0 & 4 \\
\hline & Thysanoptera & 15 & 7 & 9 & 5 & 4 & 4 & 44 \\
\hline & Hemiptera & 14 & 11 & 10 & 10 & 6 & 5 & 56 \\
\hline & Neuroptera & 0 & 0 & 1 & 0 & 1 & 0 & 2 \\
\hline & Coleoptera & 4 & 2 & 4 & 3 & 2 & 2 & 17 \\
\hline & Mecoptera & 2 & 1 & 3 & 4 & 1 & 5 & 16 \\
\hline & Diptera & 547 & 581 & 307 & 346 & 602 & 197 & 2580 \\
\hline & Lepidoptera & 10 & 5 & 7 & 10 & 4 & 6 & 42 \\
\hline & Hymenoptera & 16 & 22 & 28 & 17 & 17 & 17 & 117 \\
\hline \multirow[t]{3}{*}{ Arachnida } & Acari & 9 & 7 & 6 & 5 & 4 & 7 & 38 \\
\hline & Aranea & 4 & 4 & 7 & 7 & 5 & 7 & 34 \\
\hline & Opioliones & 5 & 3 & 3 & 4 & 4 & 0 & 19 \\
\hline
\end{tabular}

${ }^{a} M P, M$. pulcherrima; MA, M. andauensis; $M H$, M. hawaiiensis; $M L, M$. lopburiensis; $C T$, C. tephrensis; C, control.

family-level composition within Diptera was $42.8 \%$ Syrphidae, 10.1\% Sarcophagidae, 9.9\% Muscidae, 7.7\% Phoridae, 6.9\% Lauxaniidae, 5.9\% Cecidomyiidae, and 2.5\% Drosophilidae (Table 5).

Traps baited with M. pulcherrima, M. andauensis, and C. tephrensis captured significantly more individuals of the family 


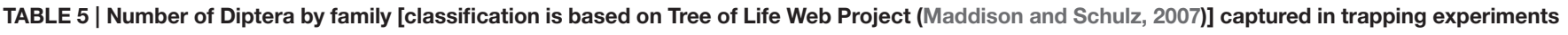
with live cultures of Metschnikowia and Cryptococcus yeasts.

\begin{tabular}{|c|c|c|c|c|c|c|c|c|}
\hline \multirow[t]{2}{*}{ Family } & \multirow[t]{2}{*}{ Main species/genus } & \multirow[t]{2}{*}{ Larval habitat } & \multicolumn{6}{|c|}{ Total no. of specimens per treatment ${ }^{a}$} \\
\hline & & & $M P$ & MA & MH & $M L$ & $C T$ & C \\
\hline Chironomidae & Chironomus sp. & Aquatic & $36 a^{b}$ & $3 b$ & $5 b$ & $3 b$ & $5 b$ & $5 b$ \\
\hline Culicidae & n.s. ${ }^{\mathrm{C}}$ & Aquatic & 0 & 1 & 0 & 0 & 0 & 0 \\
\hline Cecidomyiidae & Dasineura mali & Plant tissue & $43 a b$ & $50 a$ & $10 c$ & $16 b c$ & $23 b c$ & $25 \mathrm{bc}$ \\
\hline Tipulidae & n.s. & Saprophagous & 1 & 1 & 1 & 3 & 1 & 1 \\
\hline Phoridae & n.s. & Saprophagous & 37 & 33 & 30 & 42 & 37 & 18 \\
\hline Syrphidae & Episyrphus balteatus & Predatory, insectivorous & $237 a$ & $292 a$ & $64 b$ & 138ab & $294 a$ & $60 b$ \\
\hline$-/-$ & Sphaerophoria scripta & Predatory, insectivorous & 3 & 2 & 0 & 2 & 5 & 0 \\
\hline Lonchaeidae & n.s. & Mainly phytophagus & 12 & 24 & 7 & 0 & 5 & 7 \\
\hline Tephritidae & Rhagoletis cerasi & Frugivorous & $2 b$ & $9 a b$ & $4 b$ & $3 b$ & $14 a$ & $3 b$ \\
\hline Piophilidae & n.s. & Saprophagous & 2 & 0 & 1 & 0 & 0 & 0 \\
\hline Lauxaniidae & n.s. & Saprophagous & $34 a b$ & $24 \mathrm{bc}$ & $37 a b$ & $24 \mathrm{bc}$ & $50 a$ & $7 c$ \\
\hline Chloropidae & Chlorops pumilionis & Phytophagous & 0 & 1 & 2 & 0 & 2 & 0 \\
\hline Drosophilidae & Drosophila sp. & Saprophagous, frugivorous & $20 a$ & $25 a$ & $7 a b$ & $5 a b$ & $7 a b$ & $1 b$ \\
\hline Muscidae & n.s. & Mainly saprophagous & 20 & 28 & 11 & 19 & 24 & 5 \\
\hline Sarcophagidae & Sarcophaga sp. & Saprophagous & $37 a b$ & $43 a b$ & $52 a$ & $46 a b$ & $66 a$ & $10 b$ \\
\hline Tachinidae & n.s. & Mainly parasitoids & 30 & 19 & 16 & 19 & 32 & 30 \\
\hline Calliphoridae & Lucilia sp. & Saprophagous & 1 & 0 & 1 & 0 & 0 & 0 \\
\hline Calliphoridae & Calliphora vicina & Saprophagous & 0 & 0 & 0 & 0 & 2 & 1 \\
\hline Other & n.s. & & 32 & 26 & 59 & 26 & 35 & 25 \\
\hline
\end{tabular}

${ }^{a}$ MP, M. pulcherrima; MA, M. andauensis; MH, M. hawaiiensis; ML, M. lopburiensis; CT, C. tephrensis; C, control.

${ }^{b}$ Numbers in a row followed by the same lowercase letter are not significantly different (GLM with Poisson error distribution followed by Tukey's honestly significant difference, $P<0.05$ ). ${ }^{c}$ Not specified.

Syrphidae [mainly Episyrphus balteatus (De Geer)] compared with traps baited with $M$. hawaiiensis and control traps, while traps baited with $M$. lopburiensis were of intermediate attractivity and not different from any treatment or control (GLM, $F=$ 6.04; $d f=5,216 ; P<0.001$ ) (Table 5). Yeast-baited traps containing $M$. pulcherrima caught significantly more individuals of the family Chironomidae compared with those of the other treatments and control traps, while captures of chironomids among traps baited with $M$. andauensis, M. hawaiiensis, M. lopburiensis, C. tephrensis and control traps did not differ significantly (GLM, $F=8.65 ; d f=5,216 ; P<0.001$ ) (Table 5). Secondary growth of yeasts from the environment, which was observed only on control plates, may have resulted in attraction of chironomid flies. Traps baited with $M$. hawaiiensis and C. tephrensis captured significantly more individuals of the family Sarcophagidae (mainly Sarcophaga sp. Meigen) compared with control traps, while traps baited with M. pulcherrima, $M$. andauensis, and $M$. lopburiensis were not different from control traps (GLM, $F=4.04 ; d f=5,270 ; P<0.01$ ) (Table 5). Traps with $M$. andauensis caught similar numbers of individuals of the family Cecidomyiidae [mainly specimens of the apple leaf gall midge, Dasineura mali (Kieffer)] as $M$. pulcherrima and significantly more compared to traps baited with $M$. hawaiiensis, M. lopburiensis, C. tephrensis and control traps (GLM, $F=5.16$; $d f=5$, 270; $P<0.001$ ) (Table 5). Moreover, yeast-baited traps containing $M$. andauensis or M. pulcherrima caught significantly more individuals of the family Drosophilidae (mainly Drosophila sp. Fallén) compared with control traps. Captures of drosophilids among traps baited with $M$. hawaiiensis, M. lopburiensis, C. tephrensis and control traps did not differ significantly (GLM, $F=2.91 ; d f=5$, 54; $P<0.05$ ) (Table 5). Tephritid fruit flies were mainly represented by the European cherry fruit fly, Rhagoletis cerasi (L.) (Diptera: Tephritidae). Traps baited with $C$. tephrensis caught similar numbers of $R$. cerasi as $M$. andauensis, and significantly more individuals, compared to traps baited with $M$. pulcherrima, $M$. hawaiiensis, $M$. lopburiensis and control traps (GLM, $F=3.12 ; d f=5,216 ; P<$ 0.05) (Table 5). Phoridae were attracted to all yeast-baited traps, however catches were not significantly different to control traps (GLM, $F=3.147 ; d f=5,270 ; P=0.0754)$ (Table 5). Finally, traps baited with M. pulcherrima, M. hawaiiensis, and $C$. tephrensis captured significantly more individuals of the family Lauxaniidae compared with control traps, while attraction to traps baited with $M$. andauensis and $M$. lopburiensis were not different from control traps (GLM, $F=5.99$; $d f=5,270$; $P<0.001$ ) (Table 5).

Differences in specimen abundances as a function of trap baits were significant (GLM, $F=10.31 ; d f=5,270 ; P<0.001$ ), and, traps with M. pulcherrima, M. andauensis, and C. tephrensis captured 2.4, 2.3, and 2.4-fold, respectively, more specimens than control traps (Figure 1A). Likewise, significant differences were observed in species richness due to trap baits (GLM, $F=7.27$; $d f=5,270 ; P<0.001)$. Traps baited with $M$. pulcherrima, M. andauensis, M. hawaiiensis, M. lopburiensis and C. tephrensis 

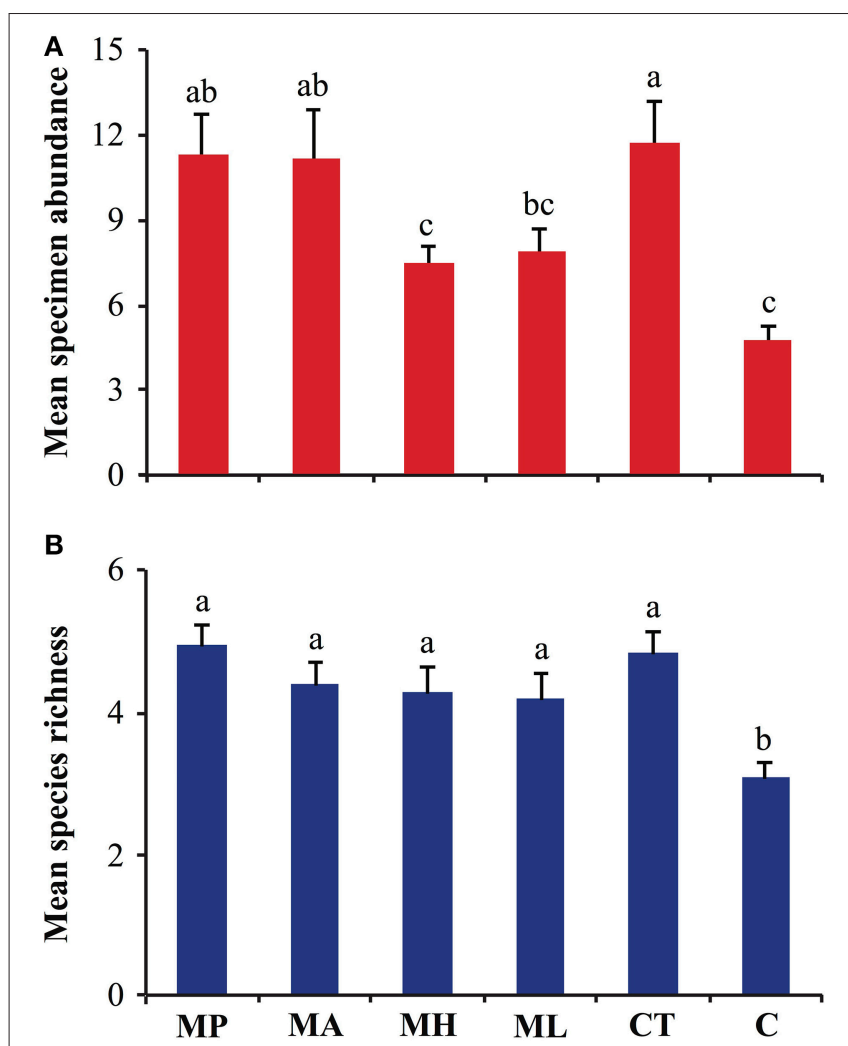

FIGURE 1 | Analysis of (A) specimen abundance, and (B) species richness of arthropod assemblages trapped with live yeast cultures $(n=6)$ in an organic apple orchard in Alnarp (Sweden), from late June to early September 2013. Bars show mean values per trap plus/minus standard error, and different lettering denotes significant differences among means (GLM with Poisson error distribution followed by Tukey's honestly significant difference, $P<0.05)$. MP, M. pulcherrima; MA, M. andauensis; $\mathrm{MH}$, M. hawaiiensis; ML, M. lopburiensis; CT, C. tephrensis; C, control.

were 1.6, 1.4, 1.4, 1.4, and 1.6-fold, respectively, more species-rich than control traps (Figure 1B).

\section{DISCUSSION}

Organic apple orchards harbor a remarkable diversity of arthropods and our trapping study shows that a diverse assemblage of 93 arthropods species, belonging to 15 orders of Insecta, Collembola, and Arachnida were attracted to traps baited with Metschnikowia and Cryptococcus live yeast cultures. Similarly, the ubiquitous yeast-like fungus Aureobasidium pullulans attracted a variety of insect taxa in spearmint fields (Davis and Landolt, 2013). This attraction was not indiscriminate, attraction to specific yeasts differed between arthropod taxa.

The majority of arthropods that were trapped in our experiments were insects (89.6\%), of which approximately $79 \%$ were flies, and most of these were hoverflies. Significantly more hoverflies were captured with traps baited with M. pulcherrima, $M$. andauensis, and C. tephrensis, compared with controls. Hoverflies exhibit a preference with respect to trap color as well as to trap height (Chen et al., 2004; Rodriguez-Saona et al., 2012).
Optimizing trap color and trap placement likely could further enhance attraction of hoverflies to yeast.

Traps baited with live cultures of $M$. pulcherrima caught significantly more chironomids, compared with the other yeasts tested and control. Chironomids are known to be highly attracted to visual and acoustic cues (Hirabayashi and Ogawa, 1999). Our report adds evidence for microbial attraction of chironomids. Furthermore, yeasts attracted flesh flies (Sarcophagidae), whereas blow flies (Calliphoridae), colonizing similar habitats (Hall and Doisy, 1993), were not significantly attracted.

Volatiles emitted by $M$. andauensis captured gall midges (Cecidomyiidae) in significant numbers, especially the apple leaf gall midge. An interaction between cecidomyiid midges and microbes was first suggested by Herman et al. (1993), who observed that A. pullulans participates in gall formation by Lasioptera ephedricola. Taken together with gall midge attraction in our study, this hints at a role of microbes in associations between phytophagous gall midges and their host plants. This is of basic interest, since many gall midges are rather specifically associated with their respective host plants. In addition, many gall midges are of economic importance (Barnes, 1951). Thus, yeast attraction may become useful in gall midge monitoring or control, for example by enhancing attractiveness of pheromone-mediated methods (Boddum et al., 2009; Hall et al., 2012).

Drosophilid fruit flies were attracted to M. pulcherrima and $M$. andauensis. It has been demonstrated that yeast attracts the fruit fly Drosophila melanogaster (Diptera: Drosophilidae) more than fruit (Becher et al., 2012). Hamby et al. (2012) showed that the spotted-wing drosophila, D. suzukii is preferentially associated with the yeast Hanseniaspora uvarum, while Cha et al. (2012, 2014) suggest fermentation volatiles to be involved in foodfinding behavior. Moreover, cup traps baited with yeast plus sugar captured more spotted-wing drosophila and nontarget organisms than vinegar baited cup traps in berry crops (Iglesias et al., 2014).

Yeast is a food resource for tephritid fruit flies (Christenson and Foote, 1960; Yee, 2008) and it is conceivable that yeast volatiles contribute to host location in these flies as well. Live cultures of $C$. tephrensis attracted a significantly higher number of European cherry fruit fly individuals than traps baited with $M$. pulcherrima and $M$. andauensis as well as control traps. Significant captures of $R$. cerasi in an apple orchard are remarkable as the flies are known to be a stenophagous species that primarily infests Prunus and Lonicera spp. (White and ElsonHarris, 1992); it could be worthwhile to investigate a possible use of C. tephrensis volatiles for monitoring or control.

All baited traps with live yeast cultures attracted flies of the families Lauxaniidae and Phoridae. Lauxaniid larvae are known to feed on microorganisms such as fungi, yeast, and bacteria (Silva and Mello, 2008). Larval feeding on fungi is also known for phorids, and adults are regarded as efficient vectors of diseases, especially in mushroom cultures. Moreover, other species such as Apocephalus borealis Brues (Diptera: Phoridae) parasitize and eventually kill bumble bees, paper wasps, and honey bees (Core et al., 2012). Leblanc et al. (2010) observed a significant attraction of phorid flies toward traps baited with Candida utilis (torula yeast) compared with traps baited only with water. Thus, baiting traps with behaviorally active yeast volatiles possibly could allow 
monitoring of the presence and abundance of phorids or even control of their population.

Our trapping study adds evidence that yeast volatiles attract a wide range of insect species. Attraction to fermentation compounds has been shown earlier for various insects (e.g., Landolt and Alfaro, 2001; Landolt et al., 2005; Becher et al., 2010; Davis et al., 2013; Cha et al., 2014). To further improve the efficacy of yeast-baited traps, additional research should be conducted to enhance attractiveness and specificity of trap lures, e.g., by using other or additional microbes, by enhancing volatile production and release, or by improving trap design. Yeast semiochemicals might contribute to improve monitoring of pest populations and establishing their economic thresholds, which is key for the implementation of successful integrated pest management (IPM) programs. Thus, we strongly suggest future work should aim at identification of yeast volatiles that elicit insect attraction. Recent work has shown that understanding of ecological interactions between yeasts and insects can lead to the development of new control strategies like efficient attractand-kill methods (Witzgall et al., 2012; Knight and Witzgall, 2013; Knight et al., 2015). Future tests might show whether additional economically important orchard insects, such as lepidopteran, tephritid, or drosophila species, can be targeted by development of innovative yeast-based control strategies. A better understanding of the behavioral physiology and ecology of insect attraction to associated yeasts will undoubtedly contribute

\section{REFERENCES}

Ahearn, D. G. (1998). "Yeast pathogenic for humans," in The Yeasts: A Taxonomic Study, eds C. P. Kurtzman and J. W. Fell (Amsterdam: Elsevier), 9-12.

Barker, J. S. F., Vacek, D. C., and East, P. D. (1988). Attraction of larvae of Drosophila buzzatii and Drosophila aldrichi to yeast species isolated from their natural environment. Aust. J. Zool. 36, 53-63. doi: 10.1071/ZO9880053

Barnes, H. F. (1951). Gall Midges of Economic Importance, Vol. 5 Gall Midges of Trees. London: Crosby Lockwood \& Son.

Becher, P. G., Bengtsson, M., Hansson, B. S., and Witzgall, P. (2010). Flying the fly: long-range flight behavior of Drosophila melanogaster to attractive odors. J. Chem. Ecol. 36, 599-607. doi: 10.1007/s10886-010-9794-2

Becher, P. G., Flick, G., Rozpedowska, E., Schmidt, A., Hagman, A., Lebreton, S., et al. (2012). Yeast, not fruit volatiles mediate Drosophila melanogaster attraction, oviposition and development. Funct. Ecol. 26, 822-828. doi: 10.1111/j.1365-2435.2012.02006.x

Boddum, T., Skals, N., Wirén, M., Baur, R., Rauscher, S., and Hillbur, Y. (2009). Optimization of the pheromone blend of the swede midge, Contarinia nasturtii, for monitoring. Pest Manag. Sci. 65, 851-856. doi: 10.1002/ps. 1762

Buser, C. C., Newcomb, R. D., Gaskett, A. C., and Goddard, M. R. (2014). Niche construction initiates the evolution of mutualistic interactions. Ecol. Lett. 17, 1257-1264. doi: 10.1111/ele.12331

Callaham, R. Z., and Shifrine, M. (1960). The yeasts associated with bark beetles. For. Sci. 6, 146-154.

Cha, D. H., Adams, T., Rogg, H., and Landolt, P. J. (2012). Identification and field evaluation of fermentation volatiles from wine and vinegar that mediate attraction of spotted wing drosophila, Drosophila suzukii. J. Chem. Ecol. 38, 1419-1431. doi: 10.1007/s10886-012-0196-5

Cha, D. H., Adams, T., Werle, C. T., Sampson, B. J., Adamczyk J. J. Jr., Rogg, H., et al. (2014). A four-component synthetic attractant for Drosophila suzukii (Diptera: Drosophilidae) isolated from fermented bait headspace. Pest Manag. Sci. 70, 324-331. doi: 10.1002/ps.3568

Chen, T.-Y., Chu, C.-C., Fitzgerald, G., Natwick, E. T., and Henneberry, T. J. (2004). Trap evaluations for thrips (Thysanoptera: Thripidae) and hoverflies to the development of new tools for monitoring and population control.

\section{AUTHOR CONTRIBUTIONS}

All authors participated in the design of the study and interpretation of the data. SA and PB prepared the yeast baits. SA performed the trapping experiments. SA wrote the first draft of the manuscript, which was edited and approved by all authors. PW supervised the project.

\section{ACKNOWLEDGMENTS}

We thank Martin Hunger for assistance during the field trapping tests. Special thanks to Julie Todd for her critically reading of and valuable suggestions for the manuscript. This study was supported by PlantLink, SLU, the Linnaeus initiative "Insect Chemical Ecology, Ethology and Evolution" (IC-E3) and the Swedish Research Council Formas (grant for young researchers).

\section{SUPPLEMENTARY MATERIAL}

The Supplementary Material for this article can be found online at: http://journal.frontiersin.org/article/10.3389/fevo. 2015.00121
(Diptera: Syrphidae). Environ. Entomol. 33, 1416-1420. doi: 10.1603/0046225X-33.5.1416

Christenson, L. D., and Foote, R. H., (1960). Biology of fruit flies. Annu. Rev. Entomol. 5, 171-192. doi: 10.1146/annurev.en.05.010160.001131

Christiaens, J. F., Franco, L. M., Cools, T. L., De Meester, L., Michiels, J., Wenseleers, T., et al. (2014). The fungal aroma gene ATF1 promotes dispersal of yeast cells through insect vectors. Cell Rep. 9, 425-432. doi: 10.1016/j.celrep.2014.09.009

Core, A., Runckel, C., Ivers, J., Quock, C., Siapno, T., Denault, S., et al. (2012). A new threat to honey bees, the parasitic phorid fly Apocephalus borealis. PLoS ONE 7:e29639. doi: 10.1371/journal.pone.0029639

Davis, T. S., Crippen, T. L., Hofstetter, R. W., and Tomberlin, J. K. (2013). Microbial volatile emissions as insect semiochemicals. J. Chem. Ecol. 39, 840-859. doi: 10.1007/s10886-013-0306-Z

Davis, T. S., and Landolt, P. J. (2013). A survey of insect assemblages responding to volatiles from a ubiquitous fungus in an agricultural landscape. J. Chem. Ecol. 39, 860-868. doi: 10.1007/s10886-013-0278-z

de Vega, C., Guzmán, B., Lachance, M.-A., Steenhuisen, S.-L., Johnson, S. D., and Herrera, C. M. (2012). Metschnikowia proteae sp. nov., a nectarivorous insectassociated yeast species from Africa. Int. J. Syst. Evol. Microbiol. 62, 2538-2545. doi: 10.1099/ijs.0.040790-0

Domingue, M. J., Pulsifer, D. P., Lakhtakia, A., Berkebile, J., Steiner, K. C., Lelito, J. P., et al. (2015). Detecting emerald ash borers (Agrilus planipennis) using branch traps baited with 3D-printed beetle decoys. J. Pest Sci. 88, 267-279. doi: 10.1007/s10340-014-0598-y

Ethiraj, S., Onkarayya, H., and Suresh, E. R. (1980). A note on the nature and sequence of yeasts during fermentation of apples grown in India. J. Appl. Bacteriol. 48, 97-100. doi: 10.1111/j.1365-2672.1980.tb05211.x

Fonseca, Á., and Inácio, J. (2006). "Phylloplane yeasts," in The Yeast Handbook: Biodiversity and Ecophysiology of Yeast, eds C. A. Rosa and G. Péter (Berlin: Springer-Verlag), 263-301.

Ganter, P. F. (2006). "Yeast and invertebrate associations," in The Yeast Handbook: Biodiversity and Ecophysiology of Yeast, eds C. A. Rosa and G. Péter (Berlin: Springer-Verlag), 303-370. 
Guzmán, B., Lachance, M.-A., and Herrera, C. M. (2013). Phylogenetic analysis of the angiosperm-fluricolous insect-yeast association: have yeast and angiosperm lineages co-diversified? Mol. Phylogenet. Evol. 68, 161-175. doi: 10.1016/j.ympev.2013.04.003

Hall, D. R., Amarawardana, L., Cross, J. V., Francke, W., Boddum, T., and Hillbur, Y. (2012). The chemical ecology of cecidomyiid midges (Diptera: Cecidomyiidae). J. Chem. Ecol. 38, 2-22. doi: 10.1007/s10886-011-0053-y

Hall, R. D., and Doisy, K. E. (1993). Length of time after death: effect on attraction and oviposition or larviposition of midsummer blow flies (Diptera: Calliphoridae) and flesh flies (Diptera: Sarcophagidae) of medicolegal importance in Missouri. Ann. Entomol. Soc. Am. 86, 589-593. doi: 10.1093/aesa/86.5.589

Hamby, K. A., Hernández, A., Boundy-Mills, K., and Zalom, F. G. (2012). Associations of yeasts with spotted-wing drosophila (Drosophila suzukii; Diptera: Drosophilidae) in cherries and raspberries. Appl. Environ. Microbiol. 78, 4869-4873. doi: 10.1128/AEM.00841-12

Herman, R. P., Bynum, H. G., and Alexander, A. B. (1993). Interaction between the black yeast Aureobasidium pullulans and the gall midge Lasioptera ephedricola in gall formation on the desert shrub Ephedra trifurca. Ecography 16, 261-268.

Hirabayashi, K., and Ogawa, K.-I. (1999). The efficiency of artificial wingbeat sounds for capturing midges in black light traps. Entomol. Exp. Appl. 92, 233-238. doi: 10.1111/j.1600-0587.1993.tb00215.x

Iglesias, L. E., Nyoike, T. W., and Liburd, O. E. (2014). Effect of trap design, bait type, and age on captures of Drosophila suzukii (Diptera: Drosophilidae) in berry crops. J. Econ. Entomol. 107, 1508-1518. doi: 10.1603/EC13538

Kaewwichian, R., Yongmanitchai, W., Kawasaki, H., and Limtong, S. (2012). Metschnikowia saccharicola sp. nov. and Metschnikowia lopburiensis sp. nov., two novel yeast species isolated from phylloplane in Thailand. Antonie van Leeuwenhoek 102, 743-775. doi: 10.1007/s10482-012-9774-3

Knight, A. L., Basoalto, E., and Witzgall, P. (2015). Improving the performance of the granulosis virus of codling moth (Lepidoptera: Tortricidae) by adding the yeast Saccharomyces cerevisiae with sugar. Environ. Entomol. 44, 252-259. doi: 10.1093/ee/nvv008

Knight, A. L., and Witzgall, P. (2013). Combining mutualistic yeast and pathogenic virus-a novel method for codling moth control. J. Chem. Ecol. 39, 1019-1026. doi: 10.1007/s10886-013-0322-Z

Lachance, M.-A. (2006). "Yeast biodiversity: how many and how much," in The Yeast Handbook: Biodiversity and Ecophysiology of Yeast, eds C. A. Rosa and G. Péter (Berlin: Springer-Verlag), 1-9.

Lachance, M.-A., Ewing, C. P., Bowles, J. M., and Starmer, W. T. (2005). Metschnikowia hamakuensis sp. nov., Metschnikowia kamakouana sp. nov. and Metschnikowia mauinuiana sp. nov., three endemic yeasts from Hawaiian nitidulid beetles. Int. J. Syst. Evol. Microbiol. 55, 1369-1377. doi: 10.1099/ijs.0.63615-0

Lachance, M.-A., Starmer, W. T., and Phaff, H. J. (1990). Metschnikowia hawaiiensis sp. nov., a heterothallic haploid yeast from Hawaiian morning glory and associated drosophilids. Int. J. Syst. Bacteriol. 40, 415-420. doi: 10.1099/00207713-40-4-415

Lachance, M.-A., Starmer, W. T., Rosa, C. A., Bowles, J. M., Barker, J. S. F., and Janzen, D. H. (2001). Biogeography of the yeasts of ephemeral flowers and their insects. FEMS Yeast Res. 1, 1-8. doi: 10.1111/j.1567-1364.2001.tb00007.x

Landell, M. F., Inácio, J., Fonseca, A., Vainstein, M. H., and Valente, P. (2009). Cryptococcus bromeliarum sp. nov., an orange-coloured basidiomycetous yeast isolated from bromeliads in Brazil. Int. J. Syst. Evol. Microbiol. 59, 910-913. doi: 10.1099/ijs.0.005652-0

Landolt, P. J., and Alfaro, J. F. (2001). Trapping Lacanobia subjuncta, Xestia cnigrum, and Mamestra configurata (Lepidoptera: Noctuidae) with acetic acid and 3-methyl-1-butanol in controlled release dispensers. Environ. Entomol. 30, 656-662. doi: 10.1603/0046-225X-30.4.656

Landolt, P. J., Pantoja, A., and Green, D. (2005). Yellowjacket wasps (Hymenoptera:Vespidae) trapped in Alaska with heptyl butyrate, acetic acid and isobutanol. J. Entomol. Soc. Brit. Columbia 102, 35-41. doi: 10.2317/601.23.1

Leblanc, L., Vargas, R. I., and Rubinoff, D. (2010). Captures of pest fruit flies (Diptera: Tephritidae) and nontarget insects in BioLure and torula yeast traps in Hawaii. Environ. Entomol. 39, 1626-1630. doi: 10.1603/EN10090

Limtong, S., and Koowadjanakul, N. (2012). Yeasts from phylloplane and their capability to produce indole-3-acetic acid. World J. Microbiol. Biotechnol. 28, 3323-3335. doi: 10.1007/s11274-012-1144-9
Maddison, D. R., and Schulz, K.-S. (2007). The Tree of Life Web Project. Available online at: http://tolweb.org

Manson, J. S., Lachance, M.-A., and Thomson, J. D. (2007). Candida gelsemii sp. nov., a yeast of the Metschnikowiaceae clade isolated from nectar of the poisonous Carolina jessamine. Antonie van Leeuwenhoek 92, 37-42. doi: 10.1007/s10482-006-9132-4

Merico, A., Sulo, P., Piskur, J., and Compagno, C. (2007). Fermentative lifestyle in yeasts belonging to the Saccharomyces complex. FEBS J. 274, 976-989. doi: 10.1111/j.1742-4658.2007.05645.x

Molnár, O., and Prillinger, H. (2005). Analysis of yeast isolates related to Metschnikowia pulcherrima the partial sequences of the large subunit rDNA and the actin gene description of Metschnikowia andauensis sp. nov. Syst. Appl. Microbiol. 28, 717-726. doi: 10.1016/j.syapm.2005.05.009

Nguyen, N. H., Suh, S. O., Erbil, C. K., and Blackwell, M. (2006). Metschnikowia noctiluminum sp. nov., Metschnikowia corniflorae sp. nov., and Candida chrysomelidarum sp. nov., isolated from green lacewings and beetles. Mycol. Res. 110, 346-356. doi: 10.1016/j.mycres.2005.11.010

Pitt, J. I., and Miller, M. W. (1968). Sporulation in Candida pulcherrima, Candida reukaufii and Chlamydozyma species: their relationships with Metschnikowia. Mycologia 60, 663-685. doi: 10.2307/3757434

Pozo, M. I., Herrera, C. M., and Bazaga, P. (2011). Species richness of yeast communities in floral nectar of southern Spanish plants. Microb. Ecol. 61, 82-91. doi: 10.1007/s00248-010-9682-x

Rodriguez-Saona, C. R., Byers, J. A., and Schiffhauer, D. (2012). Effect of trap color and height on captures of blunt-nosed and sharp-nosed leafhoppers (Hemiptera: Cicadellidae) and non-target arthropods in cranberry. Crop Prot. 40, 132-144. doi: 10.1016/j.cropro.2012.05.005

Rohlfs, M., and Kürschner, L. (2010). Saprophagous insect larvae, Drosophila melanogaster, profit from increased species richness in beneficial microbes. J. Appl. Entomol. 134, 667-671. doi: 10.1111/j.1439-0418.2009.01458.x

Silva, V. C., and Mello, R. L. (2008). Occurrence of Physoclypeus farinosus Hendel (Diptera: Lauxaniidae) in flowerheads of Asteraceae (Asterales). Neotrop. Entomol. 37, 92-96. doi: 10.1590/S1519-566X2008000100015

Stensmyr, M. C., Dweck, H. K. M., Farhan, A., Ibba, I., Strutz, A., Mukunda, L., et al. (2012). A conserved dedeicated olfactory circuit for detecting harmful microbes in Drosophila. Cell 151, 1345-1357. doi: 10.1016/j.cell.2012.09.046

Vadkertiová, R., Molnárová, J., Vránová, D., and Sláviková, E. (2012). Yeasts and yeast-like organisms associated with fruits and blossoms of different fruit trees. Can. J. Microbiol. 58, 1344-1352. doi: 10.1139/cjm-2012-0468

Vishniac, H. S. (2002). Cryptococcus tephrensis sp. nov. and Cryptococcus heimaeyensis sp. nov.; new anamorphic basidiomycetous yeast species from Iceland. Can. J. Microbiol. 48, 463-467. doi: 10.1139/w02-041

White, I. M., and Elson-Harris, M. M. (1992). Fruit Flies of Economic Significance: Their Identification and Bionomics. London: CAB International.

Witzgall, P., Proffit, M., Rozpedowska, E., Becher, P. G., Andreadis, S., Coracini, M., et al. (2012). "This is not an apple"-yeast mutualism in codling moth. J. Chem. Ecol. 38, 949-957. doi: 10.1007/s10886-012-0158-y

Woolfolk, S. W., and Inglis, G. D. (2004). Microorganisms associated with field-collected Chrysoperla rufilabris (Neuroptera: Chrysopidae) adults with emphasis on yeast symbionts. Biol. Control 29, 155-168. doi: 10.1016/S10499644(03)00139-7

Yaman, M., and Radek, R. (2008). Pathogens and parasites of the great spruce bark beetle Dendroctonus micans (Kugelann) (Coleoptera: Curculionidae, Scolytinae) from Turkey. J. Pest Sci. 81, 91-97. doi: 10.1007/s10340-0070190-9

Yee, W. L. (2008). Feeding substrates and behaviors of western cherry fruit fly (Diptera: Tephritidae). Environ. Entomol. 37, 172-180. doi: 10.1093/ee/ 37.1.172

Conflict of Interest Statement: The authors declare that the research was conducted in the absence of any commercial or financial relationships that could be construed as a potential conflict of interest.

Copyright (C) 2015 Andreadis, Witzgall and Becher. This is an open-access article distributed under the terms of the Creative Commons Attribution License (CC BY). The use, distribution or reproduction in other forums is permitted, provided the original author(s) or licensor are credited and that the original publication in this journal is cited, in accordance with accepted academic practice. No use, distribution or reproduction is permitted which does not comply with these terms. 